\title{
THEANNALS OF
}

\author{
Lung Volume Reduction Reoperations \\ Federico Tacconi, Eugenio Pompeo, Daniele Forcella, Mario Marino, Dimitrios \\ Varvaras and Tommaso C. Mineo \\ Ann Thorac Surg 2008;85:1171-1177 \\ DOI: 10.1016/j.athoracsur.2007.12.009
}

The online version of this article, along with updated information and services, is located on the World Wide Web at:

http://ats.ctsnetjournals.org/cgi/content/full/85/4/1171

The Annals of Thoracic Surgery is the official journal of The Society of Thoracic Surgeons and the Southern Thoracic Surgical Association. Copyright (C) 2008 by The Society of Thoracic Surgeons. Print ISSN: 0003-4975; eISSN: 1552-6259. 


\title{
Lung Volume Reduction Reoperations
}

\author{
Federico Tacconi, MD, Eugenio Pompeo, MD, Daniele Forcella, MD, Mario Marino, MD, \\ Dimitrios Varvaras, MD, and Tommaso C. Mineo, MD
}

Thoracic Surgery Division, Emphysema Center, Policlinico Tor Vergata University, Rome, Italy

Background. Optimal management of emphysematous patients who have lost the benefits achieved after lung volume reduction surgery is a clinical dilemma. We have hypothesized that in stringently selected instances, lung volume reduction reoperations might be considered as a salvage surgical treatment. We sought to analyze the results of a series of patients undergoing lung volume reduction reoperations after successful bilateral lung volume reduction surgery.

Methods. Between January 2000 and April 2006, 17 patients (mean age, $66 \pm 3$ years) with radiologic evidence of distinct regional lung hyperinflation underwent lung volume reduction reoperations. Surgical procedures entailed completion lobectomy in 7 patients, nonanatomic resection of lung target areas were performed in 5 patients under general anesthesia with one-lung ventilation, and awake lung plication was performed in 5 patients under sole epidural anesthesia. Follow-up at 6 and 12 months was complete in all survivors.

Results. Mean operative time was $100 \pm 12$ minutes. Two patients (11.7\%) died perioperatively of adult respi-

$\mathrm{B}^{\mathrm{i}}$ ilateral lung volume reduction surgery can produce long lasting clinical improvements in properly selected patients with upper-lobe-predominant emphysema and impaired exercise capacity [1-5]. However, due to the chronic and progressive nature of emphysema, postoperative improvements usually peak within the first 6 to 12 months and slowly decline subsequently, eventually returning back to the baseline status in many patients [5-7]. Optimal nonsurgical management of these patients is difficult owing to their poor clinical response to pharmacological therapy and is expensive because of the frequent need of outpatient or in-hospital care. Furthermore, lung transplantation can constitute an option only for individuals aged younger than 60 to 65 years, while the older population, which usually represents most of the operated on patients, enters in a desperate prospect of an irrecoverable deterioration of respiratory function and quality of life.

We have hypothesized that in stringently selected instances, lung volume reduction reoperation (LVRR) might be considered as a salvage surgical treatment. We describe the results of a consecutive series of patients

Accepted for publication Dec 3, 2007.

Address correspondence to Dr Pompeo, Cattedra di Chirurgia Toracica, Policlinico Tor Vergata, V.le Oxford 81, Rome, 00133, Italy; e-mail: pompeo@med.uniroma2.it. ratory distress syndrome. Hospital stay was $9 \pm 2$ days. Significant improvements occurred for up to 12 months in forced expiratory volume in 1 second $\left(\mathrm{FEV}_{1} ; p<0.001\right)$, forced vital capacity $(p<0.002)$, residual volume $(p<$ $0.001), 6$-minute walk test $(p<0.001)$, and modified Medical Research Council dyspnea index $(p<0.001)$. At 6-months, improvements in $\mathrm{FEV}_{1}$ were greater than 200 $\mathrm{mL}$ in 11 patients and correlated with the postoperative reduction in residual volume $(r=-0.62, p=0.01)$; baseline residual volume was inversely correlated with the degree of improvement in the dyspnea index $(r=$ $-0.54, p=0.03$ ).

Conclusions. Lung volume reduction reoperations can offer significant clinical improvement to stringently selected patients who have lost the clinical benefit achieved after lung volume reduction surgery.

(Ann Thorac Surg 2008;85:1171-7)

(C) 2008 by The Society of Thoracic Surgeons

undergoing LVRR after previous successful lung volume reduction surgery.

\section{Material and Methods}

Between January 2000 and April 2006, 17 patients (mean age, $66 \pm 3$ years) underwent LVRR. Procedures were completion lobectomy in 7 patients, nonanatomic resection of the most hyperinflated lung regions in 5 patients under general anesthesia, and awake lung plication under thoracic epidural anesthesia in 5 patients [8]. All patients gave written informed consent for the procedure, and the Tor Vergata Ethical Committee approved the study.

Completion lobectomy was planned in the presence of radiologic and scintigraphic evidence of a completely destroyed upper lung lobe. Nonanatomic resection, or more recently, awake lung plication were planned in presence of distinct regional hyperinflated lung areas, possibly located distant from the site of previous volume reduction.

All patients underwent a standardized preoperative workup, including a pulmonary function test, plethysmography, single-breath diffusing capacity for carbon monoxide (DLCO), blood gases assay, echocardiography, 6-minute walk test (6MWT), in-expiratory roentgenograms, high-resolution computed tomography (CT), and 
Table 1. Inclusion Criteria

- Meaningful clinical improvements after previous bilateral lung volume reduction surgery.

- Patient's motivation for reoperation.

- Deterioration of dyspnea to presurgical level, refractory to maximal medical therapy.

- Evidence of heterogeneous emphysema at the high resolution computed tomography (degree of heterogeneity $>$ 1 at visual scoring classification).

- Radiologic evidence of distinct regional hyperinflation of the lungs with residual volume determined by body plethysmography $\geq 150 \%$ predicted.

- Body mass index $>19 \mathrm{~kg} / \mathrm{m}^{2}$.

- Mean pulmonary artery pressure $<35 \mathrm{~mm} \mathrm{Hg}$.

- Arterial carbon dioxide tension $<55 \mathrm{~mm} \mathrm{Hg}$.

- Diffusing capacity for carbon monoxide $>20 \%$ predicted.

- Ascertained smoking cessation since 4 months.

- American Society of Anesthesiology score $\leq 3$

- Age $<80$ years.

- Not prevailing chronic bronchitis symptoms or recent ( $<6$ week) acute exacerbation.

- Absence of significant comorbidity:

- Cor pulmonale

- Unstable angina or recent ( $<6$ months) myocardial infarction

- History of malignancies $\leq 5$ years (including early cancers)

- Unstable diabetes mellitus

- Need of oral steroids $<16 \mathrm{mg} / \mathrm{d}$

- No history of major complications after previous lung volume reduction surgery

radionuclide lung perfusion scan. In particular, the severity and distribution of emphysema were assessed accordingly to a previously validated CT-based visual scoring system $[9,10]$.

Briefly, with high resolution CT, 6 standard lung scans are obtained from the apex to base as reference levels. The severity of emphysema is graded in each CT layer by estimating the percentage of destroyed lung tissue as grade $1,0 \%$ to $25 \%$; grade $2,25 \%$ to $50 \%$; grade $3,50 \%$ to $75 \%$, and grade 4 , exceeding $75 \%$; thus, values per each side range from 6 to 24 . In each lung, the difference between the median severity score in the three worst sections and the three best sections are calculated to express the degree of heterogeneity between within the lungs (range, 0 to 3 ).

The asymmetric ratio of emphysema (ARE) reflects the difference of severity between the lungs and is expressed as the ratio between severity scores. The ARE is also influenced by regional lung hyperinflation, which was estimated by measuring the degree of mediastinal switch from the midline. A deviation of at least $1 \mathrm{~cm}$ adds a score of 0.1 to ARE. An ARE exceeding 1.1 indicates patients with asymmetric emphysema that are candidates for a unilateral procedure. Finally, the degree of hyperinflation (range, 1 to 4 ) is expressed on the basis of the amplitude of diaphragmatic excursion, calculated by superimposing the inspiratory and expiratory roentgenograms.

Eligibility criteria for LVRR are reported in Table 1. Contraindications included history of major morbidity or unsatisfactory outcome after primary lung volume reduction surgery, or both, associated bronchitis with sputum production, body mass index of less than $19 \mathrm{~kg} / \mathrm{m}^{2}$, continuing smoking habit, and comorbid conditions implying an unacceptable procedure-related risk (Table 1). Coagulation defects, unfavorable anatomy for the placement of epidural catheter, psychiatric disorders, or preference for general anesthesia were considered main contraindications for the awake LVRR. All patients underwent clinical assessment for reoperation after a 6-week respiratory rehabilitation program.

Operative time and technical feasibility, scored by the surgeon into 4 grades from $1=$ poor to $4=$ excellent, were considered variables reflecting the technical difficulty during the operation. Intraoperative and perioperative changes in the ratio of arterial oxygen tension to fraction of inspired oxygen $\left(\mathrm{PaO}_{2} / \mathrm{FIO}_{2}\right)$ and arterial carbon dioxide tension $\left(\mathrm{PaCO}_{2}\right)$ were considered measures of respiratory impairment.

After the operation, patients were followed up monthly for the first 3 months and then every 3 months. Lung function data collected at the 6- and 12 month follow-up were used for statistical analysis.

\section{Statistics Analysis}

Data are presented as mean \pm standard deviation. Owing to the limited sample size and the nonnormal distribution of data, the nonparametric Mann-Whitney and Wilcoxon tests were used for comparison of unpaired and paired data, respectively. Correlations were assessed with Spearman coefficients. Frequencies were assessed by a two-tailed Fischer exact test.

\section{Surgical Technique}

All surgical procedures were performed with the patient in the full lateral decubitus position.

COMPLETION LOBECTOMY. The operation was performed either by video-assisted minithoracotomy or lateral thoracotomy under general anesthesia with one-lung ventilation. Isolation of hilar structures was done in a standard manner whenever anatomic fissures were complete; otherwise, a nonbuttressed staple resection of the upper lobe was performed, without dissection of the fissure, to reduce the risk of postoperative air leaks.

NONANATOMIC LUNG RESECTION. This was always performed by a video-assisted thoracoscopic approach under general anesthesia with one-lung ventilation. Four flexible trocars were inserted. A $0^{\circ}, 10-\mathrm{mm}$ camera was used. Resection of the most hyperinflated lung regions was performed with the aid of a nonbuttressed 45- $\mathrm{mm}$ endostapler after adhesiolysis and wide isolation of the targeted lung areas. Whenever the hyperinflated lung region was located distant from the superior segment of the upper lobe, adhesions in the pleural dome were not completely dissected free to facilitate postoperative lung reexpansion.

AWAKE LUNG PLICATION. Through a video-assisted thoracoscopic approach, a $30^{\circ}, 10-\mathrm{mm}$ camera was used to facilitate oblique vision of the lung during spontaneous 
Table 2. Overall Mean Postoperative Changes of Lung Volume Reduction Reoperation at 6 and 12 Months

\begin{tabular}{|c|c|c|c|c|c|}
\hline Variable & Baseline & Post-op 6 Months & $p$ Value & Post-op 12 Months & $p$ Value \\
\hline $\mathrm{FEV}_{1}, \mathrm{~L}$ & $0.71 \pm 0.1$ & $0.90 \pm 0.2$ & $<0.001$ & $0.89 \pm 0.2$ & $<0.001$ \\
\hline $\mathrm{FEV}_{1}, \%$ pred & $26 \pm 3$ & $31 \pm 6$ & 0.01 & $30 \pm 6$ & 0.01 \\
\hline FVC (L) & $1.86 \pm 0.2$ & $2.26 \pm 0.2$ & $<0.001$ & $2.20 \pm 0.2$ & 0.002 \\
\hline FVC, $\%$ predicted & $55 \pm 6$ & $67 \pm 9$ & 0.001 & $63 \pm 8.5$ & $<0.001$ \\
\hline $\mathrm{RV}, \mathrm{L}$ & $4.81 \pm 0.6$ & $4.03 \pm 0.5$ & $<0.001$ & $4.3 \pm 0.5$ & $<0.001$ \\
\hline RV, \% predicted & $217 \pm 15$ & $176 \pm 13$ & $<0.001$ & $186 \pm 20$ & $<0.001$ \\
\hline TLC, L & $6.7 \pm 0.5$ & $6.3 \pm 0.4$ & 0.002 & $6.6 \pm 0.6$ & 0.06 \\
\hline TLC, \% predicted & $122 \pm 10$ & $113 \pm 9$ & 0.006 & $119 \pm 7$ & 0.43 \\
\hline $\mathrm{DLCO}, \mathrm{mmol} / \mathrm{kPa} / \mathrm{min}$ & $3.4 \pm 1.0$ & $3.6 \pm 0.9$ & 0.23 & $3.5 \pm 0.9$ & 0.47 \\
\hline DLco, \% predicted & $44 \pm 11$ & $46 \pm 9$ & 0.23 & $45 \pm 8$ & 0.37 \\
\hline $6 \mathrm{MWT}, \mathrm{m}$ & $248 \pm 60$ & $329 \pm 70$ & 0.001 & $308 \pm 68$ & 0.001 \\
\hline $\mathrm{PaO}_{2}, \mathrm{~mm} \mathrm{Hg}$ & $59 \pm 2$ & $62 \pm 2$ & 0.007 & $61 \pm 2$ & 0.02 \\
\hline $\mathrm{PaCO}_{2}, \mathrm{~mm} \mathrm{Hg}$ & $44.5 \pm 2.8$ & $44 \pm 2$ & 0.79 & $44.5 \pm 2.5$ & 0.94 \\
\hline Dyspnea (MMRC score) & $3.5 \pm 0.5$ & $2.4 \pm 0.6$ & 0.003 & $2.6 \pm 0.6$ & 0.003 \\
\hline
\end{tabular}

6MWT $=6$-minute walk test; $\quad$ DLCo $=$ diffusion capacity of carbon monoxide; $\quad \mathrm{FEV}_{1}=$ forced expiratory volume in 1 second; $\quad$ FVC $=$ forced vital capacity; $\quad \mathrm{MMRC}=$ Modified Medical Research Council; $\quad \mathrm{PaCO}_{2}=$ arterial carbon dioxide tension; $\quad \mathrm{PaO}{ }_{2}=$ arterial oxygen tension; $\mathrm{RV}=$ residual volume; TLC = total lung capacity.

ventilation. The lung target areas were visualized and introflexed with a cotton swab while 2 ring forceps were used to gently grasp the redundant lung edges. Subsequently, both lung edges were grasped together and sutured with a $45-\mathrm{mm}$ no-knife endostapler (Endopath 45, Ethicon Endosurgery, Pomezia, Italy) to perform an introflexing plication of the targeted lung region [8].

At the completion of the procedure, 1 or 2 chest tubes were inserted, depending on the extent of adhesiolysis performed, and connected to a water seal. Mild suction was applied in case of major air leaks with pneumothorax exceeding one-third of the pleural cavity.

Criteria for discharge were standardized and included stable clinical condition, radiologically documented complete lung reexpansion, and fluid loss of less than $200 \mathrm{~mL}$ in 24 hours. Patients with minimal air leaks and no pleural space problems were discharged with a Heimlich valve provided they could receive domiciliary assistance and could reach the hospital within about 30 minutes from home. All patients underwent a 4-week postoperative respiratory rehabilitation program.

\section{Results}

\section{Historical Data}

The study cohort represents the $8.4 \%$ of the 202 patients treated by lung volume reduction at our center up to April 2006. Four patients who were initially considered eligible for reoperation by the preliminary workup were eventually excluded because 2 patients refused and 2 had unconfessed continuing smoking. In the same period, 3 other patients were scheduled for lung transplantation on the basis of age ( $<55$ years) and homogeneous distribution of disease.

In the study cohort, previous bilateral thoracoscopic lung volume reduction surgery was done as a simultaneous or staged procedure in 6 and 11 patients, respec- tively. All patients had upper-lobe-predominant emphysema related to cigarette smoking and underwent bilateral thoracoscopic resection of the most destroyed lung regions. Bovine pericardium buttress was used in 4 patients. Postoperative complications were prolonged air leaks ( $>7$ days) in 5 patients and acute lung injury in 1. All patients experienced clinical improvements during follow-up. The interval between the primary lung volume reduction operation and the reoperation averaged $56 \pm 8$ months.

\section{Baseline Assessment}

Demographics and preoperative data are summarized in Tables 2 and 3. In all instances, we have found imagingbased evidence of severe emphysema with distinct heterogeneity and marked hyperinflation. According to our radiologic morphology visual scoring system, median emphysema severity in the side targeted for reoperation was $18 \pm 2$, with a hyperinflation score of $3.4 \pm 0.6$. The asymmetric ratio of emphysema between the lungs averaged $1.22 \pm 0.13$. The mean degree of heterogeneity within the lung was $1.76 \pm 0.4$ (range, 0 to 3 ).

\section{Operative Results}

There were 11 right and six left procedures. The mean operative time was $100 \pm 12$ minutes. The feasibility score averaged $2.6 \pm 0.2$, with no difference between general and awake anesthesia groups. Completion lobectomy was done with standard isolation of pulmonary artery branches in 3 patients and without dissection in the fissure in 4 patients. No patient undergoing thoracoscopic LVRR required conversion to thoracotomy, and no patient undergoing an operation while awake required conversion to general anesthesia.

Operative mortality was $11.7 \%$ and included 2 patients operated on under general anesthesia (one completion lobectomy and one nonanatomic lung resection) who 
Table 3. Main Individual Findings

\begin{tabular}{|c|c|c|c|c|c|c|c|c|c|c|}
\hline Patient & Age & Sex & Intervention & $\begin{array}{c}\text { Reoperation } \\
\text { Site }\end{array}$ & Morbidity & $\begin{array}{l}\text { Hospital } \\
\text { Stay }\end{array}$ & $\begin{array}{c}\text { 12-mo } \\
\Delta \text { Dyspnea } \\
\text { Grade }\end{array}$ & $\begin{array}{c}12 \mathrm{mo}^{2} \\
\Delta \mathrm{FEV}_{1} \\
(\mathrm{~mL})\end{array}$ & $\begin{array}{c}12 \mathrm{mo} \\
\Delta 6 \mathrm{MWT} \\
(\%)\end{array}$ & Status (months) \\
\hline 1 & 63 & M & CL & RUL & None & 10 & -1 & +60 & 26 & Alive (60) \\
\hline 2 & 66 & M & CL & LUL & $\begin{array}{l}\text { Air leaks, ARDS } \\
\text { (dead) }\end{array}$ & 7 & $\cdots$ & $\ldots$ & $\ldots$ & $\ldots$ \\
\hline 3 & 65 & M & CL & RUL & Air leaks & 10 & 0 & +220 & 23.5 & Alive (48) \\
\hline 4 & 71 & M & CL & RUL & None & 8 & 0 & +240 & 23 & Alive (36) \\
\hline 5 & 64 & $\mathrm{~F}$ & $\mathrm{CL}$ & RUL, ML & None & 12 & -2 & +200 & 40 & Alive (48) \\
\hline 6 & 59 & M & CL & LUL & Atrial fibrillation & 8 & -1 & +180 & 47 & $\begin{array}{l}\text { Alive, listed for } \\
\text { LTx (24) }\end{array}$ \\
\hline 7 & 61 & M & CL & RUL, RLL & Bleeding, air leaks & 9 & -2 & +330 & 105 & $\begin{array}{l}\text { Alive, listed for } \\
\text { LTx (33) }\end{array}$ \\
\hline 8 & 68 & $\mathrm{~F}$ & SR & Lingula & Air leaks & 14 & 0 & +10 & 36 & Dead (RF, 18) \\
\hline 9 & 68 & M & SR & RUL & ARDS (dead) & 15 & $\ldots$ & $\ldots$ & $\ldots$ & $\ldots$ \\
\hline 10 & 67 & M & SR & LUL & None & 7 & -1 & +190 & 47 & Alive (24) \\
\hline 11 & 68 & M & SR & RUL & None & 9 & 0 & +70 & 18 & Dead (NSCLC, 18) \\
\hline 12 & 69 & M & SR & RUL + RLL & Difficult weaning & 8 & 0 & +150 & 11 & Dead (MOF, 22) \\
\hline 13 & 68 & M & $\mathrm{AP}$ & LLL & Air leaks & 7 & -1 & +270 & 10.5 & Alive (24) \\
\hline 14 & 71 & $\mathrm{~F}$ & $\mathrm{AP}$ & RUL, ML & None & 6 & -1 & +230 & -6.6 & Alive (12) \\
\hline 15 & 65 & M & $\mathrm{AP}$ & LUL & Air leaks & 10 & -1 & +110 & 90.5 & Alive (18) \\
\hline 16 & 71 & M & $\mathrm{AP}$ & RUL & None & 6 & 0 & +20 & 26.6 & Alive (12) \\
\hline 17 & 64 & M & $\mathrm{AP}$ & ML & Air leaks & 7 & -1 & +270 & 40 & Alive (12) \\
\hline
\end{tabular}

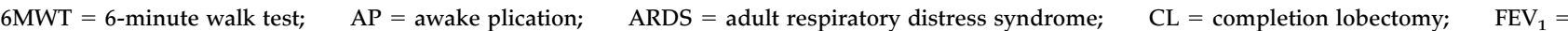
forced expiratory volume in 1 second; $\quad$ LLL = left lower lobe; $\quad$ LTx = lung transplantation; LUL = left upper lobe; $\quad$ ML = medium lobe; $\quad \mathrm{MOF}=$ multi organ failure; $\quad \mathrm{NSCLC}=$ non-small cell lung cancer; $\quad \mathrm{RF}=$ respiratory failure; RLL = right lower lobe; $\quad \mathrm{RUL}=\mathrm{right}$ upper lobe; $\quad \mathrm{SR}=$ stapled resection.

died postoperatively on day 7 and 15 , respectively, of adult respiratory distress syndrome (ARDS). One patient undergoing nonanatomic lung resection under general anesthesia required assisted ventilation for 5 hours but was eventually weaned and thereafter had an uneventful postoperative recovery. Morbidity included prolonged air leaks in 7 patients, and 1 patient each presented with symptomatic arrhythmia (high-frequency atrial fibrillation) and controlled bleeding. Hospital stay averaged $9 \pm$ 2 days.

\section{Clinical Results}

Six months after the operation, significant improvements occurred in forced expiratory volume in 1 second $\left(\mathrm{FEV}_{1}\right)$, forced vital capacity (FVC), residual volume (RV), total lung capacity, 6MWT, and dyspnea index (Table 2). In particular, 11 patients $(73.3 \%)$ showed a meaningful improvement in $\mathrm{FEV}_{1}(\geq 200 \mathrm{~mL})$ or FVC $(\geq 400 \mathrm{~mL})$, or both. All survivors had a meaningful decrease in RV $(\geq 500$ mL). Mean resting $\mathrm{PaO}_{2}$ also improved slightly after LVRR, although no patient experienced any remarkable change in daily oxygen requirement. No significant change occurred in Dlco and $\mathrm{PaCO}_{2}$.

The $6 \mathrm{MWT}$ improved by more than $70 \mathrm{~m}$ in 10 patients $(58.8 \%)$, remained substantially unchanged in $4(23.5 \%)$, and deteriorated slightly $(-20 \mathrm{~m})$ in $1(5.8 \%)$. Overall, the mean percentage of improvement of $37 \% \pm 29 \%$ was widely dispersed (range, $11 \%$ to $105 \%$ of presurgical values.) The greatest changes were observed in patients with a very low baseline exercise capacity as indicated by a 6 MWT of less than $200 \mathrm{~m}$.

The modified Medical Research Council (MMRC) dyspnea index improved postoperatively in 11 patients $(64.7 \%)$. In particular, it reduced by 2 degrees in 5 patients and by 1 degree in 6 patients. At 12 months, improvements in $\mathrm{FEV}_{1}, \mathrm{FVC}$, and RV remained sustained in 7 of the 11 responder patients; conversely, these outcome measures deteriorated in 4 patients.

The dyspnea score remained improved for up to 12 months in 9 patients $(52.9 \%)$ but returned to the preoperative values in 2. Improvements in the 6MWT were still sustained at 12 months in 7 patients but deteriorated in 2.

At univariate analysis, the magnitude of improvement in dyspnea index was inversely correlated with baseline $\mathrm{RV}$. Absolute improvements in $\mathrm{FEV}_{1}$ at 6 and 12 months correlated with the postoperative percentage decrease in RV (Fig 1). Main individual preoperative and postoperative findings are detailed in Table 3.

Intergroup comparisons showed that the awake and general anesthesia subgroups were relatively well matched in baseline measures (data not shown). Comparative perioperative results are reported in Table 4 and show that intraoperatively, the $\mathrm{PaCO}_{2}$ rose to higher values in the awake group. At 24 hours after the procedure, the $\mathrm{PaO}_{2} / \mathrm{FIO}_{2}$ ratio was better in the awake group, and the $\mathrm{PaCO}_{2}$ returned within normal values in both groups. The average amplitude of functional and subjec- 

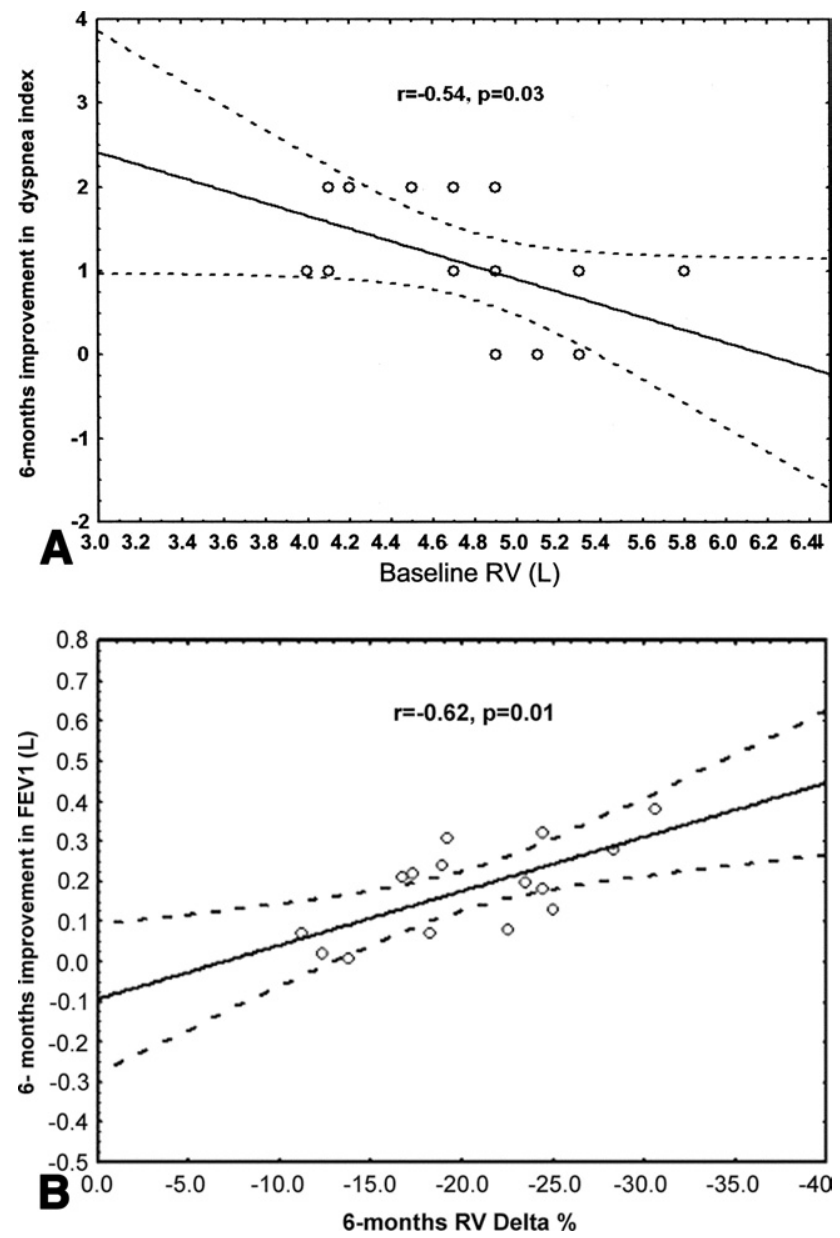

Fig 1. Scatterplots show the relationships between (A) improvement in the dyspnea index at 6 months vs baseline residual volume (RV) and (B) postoperative change in forced expiratory volume in 1 second $\left(F E V_{1}\right)$ vs the postoperative change in residual volume $(\Delta R V)$. The solid lines are the linear regressions, while the dotted lines represent the 95\% confidence interval. The Spearman correlation coefficient $(r)$ and $p$ values are shown.

tive postoperative changes was similar between the groups, although there was a trend toward a lesser amplitude of change in $\mathrm{FEV}_{1}$ and RV in patients undergoing an awake reoperation.

\section{Comment}

The increasing number of lung volume reduction procedures performed worldwide have led to questions about how to manage patients who have lost the clinical benefit achieved with surgical treatment. In fact, although in some of these patients surgical reevaluation is theoretically possible, the role of LVRR has been poorly investigated so far, probably reflecting a reluctance to consider a redo operation in such a high-risk population.

In 2000, Stammberger and coworkers [11] first reported satisfactory results of LVRR in a patient with $\alpha-1$ antitrypsin deficiency-related emphysema. More recently, we have shown that completion lobectomy can offer mean- ingful improvements in properly selected patients who previously underwent successful bilateral lung volume reduction procedures [12].

The present study adds to the findings that LVRR can ameliorate symptoms and improve lung function for at least 1 year in a significant number of selected patients. On the other hand, a note of caution is raised by the high ARDS-related mortality rate of $11.7 \%$ observed in our series. This complication has been reported to occur more frequently after redo operations [13] and is almost invariably fatal when it develops in subjects with severely impaired lung function.

In this retrospective analysis, the decline in $\mathrm{FEV}_{1}$ after the completion of previous bilateral lung volume reduction surgery averaged $117 \pm 28 \mathrm{~mL}$ per year (range, 80 to 159 $\mathrm{mL}$ ). This value is similar to that reported by Brenner and coworkers [7] in patients undergoing unilateral procedures and is somewhat less than that reported by Traveline and coworkers [14] after bilateral one-stage operations.

We believe that such a relatively slow functional decay might imply a less aggressive progression of disease in this particular subgroup, possibly related to a better preservation of functional tissue despite the development of regionally hyperinflated areas. Regional differences in elastic recoil resulting from previous operations could be at the basis of this behavior [15] and have also been suggested as a possible cause of giant bulla formation after lung volume reduction operations [16]. Hence, we hypothesize that amongst patients undergoing lung volume reduction procedures, those who show a less steep functional decline after an initial clinical improvement are more likely to become candidates for a reoperation subsequently. Lung volume reduction reoperations could be thus considered in stringently selected instances within a step-by-step strategy aimed at prolonging at most the benefit of the procedure.

On the basis of our previous experience with awake lung volume reduction operations under epidural anes-

Table 4. Comparison of Perioperative and Postoperative Results Between Study Groups

\begin{tabular}{lccc}
\hline Variable & $\begin{array}{c}\text { Awake } \\
(\mathrm{n}=5)\end{array}$ & $\begin{array}{c}\text { General Anesthesia } \\
(\mathrm{n}=12)\end{array}$ & $p$ Value \\
\hline Operative time & $91 \pm 10$ & $103 \pm 10$ & 0.039 \\
Feasibility & $2.6 \pm 0.5$ & $2.5 \pm 2$ & 0.78 \\
Intra-op $\mathrm{PaO}_{2} / \mathrm{FIO}_{2}$ & $265 \pm 32$ & $260 \pm 83$ & 0.50 \\
Intra-op $\mathrm{PaCO}_{2}$ & $56 \pm 3.6$ & $47 \pm 4$ & 0.003 \\
Post-op $\mathrm{PaO}_{2} / \mathrm{FIO}_{2}$ & $294 \pm 32$ & $256 \pm 36$ & 0.04 \\
Post-op $\mathrm{PacO}_{2}$ & $45.8 \pm 3.7$ & $47.7 \pm 2$ & 0.23 \\
Hospital stay & $7.2 \pm 1.6$ & $9.7 \pm 2.6$ & 0.032 \\
$\Delta$ FEV $\%$ & $19.7 \pm 11$ & $29.2 \pm 4.8$ & 0.20 \\
$\Delta \mathrm{RV}^{2} \%$ & $-13.8 \pm 4.0$ & $-16.2 \pm 4.8$ & 0.44 \\
$\Delta 6 \mathrm{MWT} \%$ & $32.2 \pm 37$ & $32.6 \pm 30$ & 0.86 \\
$\Delta$ Dyspnea & $-1.2 \pm 0.8$ & $-1.0 \pm 0.8$ & 0.67 \\
\hline
\end{tabular}

$6 \mathrm{MWT}=6$-minute walk test; $\quad \mathrm{FEV}_{1}=$ forced expiratory volume in 1 second; $\quad \mathrm{FIO}_{2}=$ fraction of inspired oxygen; $\quad \mathrm{PaCO}_{2}=$ arterial carbon dioxide tension; $\quad \mathrm{PaO}_{2}=$ arterial oxygen tension; $\quad \mathrm{RV}=$ residual volume. 
thesia [8], we have recently decided to use the same approach to perform LVRR in an attempt to minimize morbidity by avoiding adverse effects related to general anesthesia. Our main concern in this regard was initially related to the presence of pleural adhesions resulting from the previous procedure, particularly when bovine pericardium buttress had been used. Instead, we have noticed that even under sole epidural anesthesia and spontaneous ventilation, pleural adhesions could be dissected free, although surgical maneuvers were more technically demanding. We have also found that the lung regions targeted for LVRR were frequently localized distant from those targeted for the initial lung volume reduction, a feature that rendered often unnecessary a wide adhesiolysis at that level.

As a whole, functional and subjective results of the awake LVRR were satisfactory. Moreover, none of the patients undergoing an awake procedure died or had major morbidity. We hypothesize that avoidance of ventilator-related trauma might have facilitated a faster recovery by avoiding life-threatening complications in this subgroup [17].

Postoperative improvements in subjective dyspnea and airflow obstruction occurred in a significant number of patients independent of the surgical approach. Not surprisingly, the absolute gain in $\mathrm{FEV}_{1}$ correlated with the degree of reduction in $\mathrm{RV}$, in agreement with the pathophysiologic principle of lung volume reduction in itself, which implies improved lung dynamics as a consequence of surgical resizing of the lung [18]. Conversely, no significant correlations were found between the degree of improvement in subjective dyspnea and postoperative changes in $\mathrm{FEV}_{1}$, FVC, and RV. In particular, we noticed that the dyspnea index in 5 patients improved after LVRR without a parallel increase in $\mathrm{FEV}_{1}$ or $\mathrm{FVC}$, or both.

Several conjectural reasons could determine symptomatic benefit in these patients. An increase in static elastic recoil, which has been indicated as one of the main physiologic effects of lung volume reduction and can occur irrespective of the degree of functional improvement [19], could translate into reduced expiratory effort at tidal breathing. An alternative interpretation is that in some patients, the increase in elastic recoil after lung volume reduction can improve airflow until a critical point governed by the degree of associated chronic bronchitis and small airways disease is reached. It is thus likely that in these instances, relief of symptoms should be attributed to other physiologic effects, including relief of compressive effects of hyperinflated lung tissue on the heart chambers and great vessels [20] or improvement in venous return due to reconfiguration of the diaphragm dome, or both.

The encouraging results of this series must be interpreted with caution. In fact, LVRR is more technically demanding than the primary lung volume reduction operation and is a potentially dangerous procedure owing to the increased risks of ARDS. For this reason, we would stress the importance of a careful preoperative assessment of candidates, who must strictly satisfy the selection criteria. In particular, we advise that once the eligibility of the surgical candidate is determined, LVRR should be performed only in patients who already benefited meaningfully after the first volume reduction because it is highly unlikely that a patient who did not improve initially will respond satisfactorily to reoperation.

Pros and cons of LVRR must be balanced against other alternative therapeutic options, which include lung transplantation for patients younger than 60 to 65 years, and comprehensive medical treatment for the remaining patients. In patients who are suitable for lung transplantation, LVRR might even be used as a bridge to the transplant. Indeed, recent reports have pointed out that lung volume reduction did not increase transplantationrelated risks [21] and resulted in better posttransplant outcome by improving general health status [22, 23]. Furthermore, in patients scheduled for unilateral lung transplantation, LVRR could reduce the risk of posttransplant hyperinflation in the contralateral lung [24].

We acknowledge some limitations of our study. First, our analysis is limited to the 12-month follow-up. This boundary was selected assuming that benefits of this unorthodox surgical treatment are not expected to last as long as after primary lung volume reduction. Second, because of the retrospective nature of the study, a comparative evaluation of postoperative results might have been affected by preexisting differences in disease morphology rather than by the chosen surgical approach. Finally, because awake procedures embrace a more recent period of our experience, results in this subgroup might have been positively affected by a learning curve effect. On the other hand, patients undergoing awake reoperation were substantially similar to those undergoing LVRR under general anesthesia in terms of demographics, radiologic morphology patterns, degree of airflow obstruction, and subjective impairment (data not shown).

In conclusion, our study suggests that LVRR, including completion lobectomy, nonanatomic lung resection, and even awake lung plication of hyperinflated lung regions can be useful to manage selected patients who have marked functional decay some years after successful bilateral lung volume reduction. Further investigation is welcome to implement our preliminary encouraging findings.

\section{References}

1. Naunheim KS, Wood DE, Mohsenifar Z, et al. Long-term follow-up of patients receiving lung-volume reduction surgery versus medical therapy for emphysema by the National Emphysema Treatment Trial Research Group. Ann Thorac Surg 2006;82:385-7.

2. Miller JD, Malthaner RA, Goldsmith $\mathrm{CH}$, et al. Canadian Lung Volume Reduction Surgery Study. A randomized clinical trial of lung volume reduction surgery versus best medical care for patients with advanced emphysema: a two-years study from Canada. Ann Thorac Surg 2006; 81:314-320.

3. Appleton S, Adams R, Porter S, Peacock M, Ruffin R. Sustained improvements in dyspnea and pulmonary function 3 to 5 years after lung volume reduction surgery. Chest 2003; 123:1838-46. 
4. Ciccone AM, Meyers BF, Guthrie TJ, et al. Long-term outcome of bilateral lung volume reduction in 250 consecutive patients with emphysema. J Thorac Cardiovasc Surg 2003; 125:513-25.

5. Gelb AF, McKenna Jr, Brenner M, Epstein JD, Zamel N. Lung function volume reduction surgery $5 \mathrm{yr}$ after lung volume reduction surgery. Am J Respir Crit Care Med 2001;163:1562-6.

6. Bloch KE, Georgescu CL, Russi EW, Weder W. Gain and subsequent loss of lung function after lung volume reduction surgery in case of severe emphysema with different morphologic patterns. J Thorac Cardiovasc Surg 2002;123: 845-6.

7. Brenner M, McKenna Jr RJ, Gelb AF, Fischel RJ, Wilson A. Rate of FEV1 change following lung volume reduction surgery. Chest 1998;113:652-9.

8. Mineo TC, Pompeo E, Mineo D, Tacconi F, Marino M, Sabato AF. Awake nonresectional lung volume reduction surgery. Ann Surg 2006;243:131-6.

9. Mineo TC, Pompeo E, Mineo D, Rogliani P, Leonardis C, Nofroni I. Results of unilateral lung volume reduction surgery in patients with distinct heterogeneity between lungs. J Thorac Cardiovasc Surg 2005;129:73-9.

10. Pompeo E, Sergiacomi G, Nofroni I, Roscetti W, Simonetti G, Mineo TC. Morphologic grading of emphysema is useful in the selection of canididates for unilateral or bilateral reduction pneumoplasty. Eur J Cardiothorac Surg 2000;17:680-6.

11. Stammberger U, Thurnheer R, Schmid RA, Russi EW, Weder $W$. Redo lung volume reduction surgery in a patient with $\alpha-1$-antitrypsin deficiency. Ann Thorac Surg 2000;69:632-3.

12. Pompeo E, Mineo D, Bollero P, Rogliani P, Ambrogi V, Mineo TC. Completion lobectomy after bilateral lung volume reduction for emphysema: salvage option or fancy? J Thorac Cardiovasc Surg 2004;127:1212-4.

13. Verheijen-Breemhaar L, Boogard JM, Van den Berg B, et al. Postpneumonectomy pulmonary oedema. Thorax 1988;43: 323-6.
14. Traveline JM, Gaughan JP, Furukawa S, Criner GJ. Effect of bilateral lung volume reduction surgery on FEV1 decline in severe emphysema. COPD 2005;2:203-8.

15. West JB. Distribution of mechanical stress in the lung, a possible factor in localization of pulmonary disease. Lancet 1971;2:839-41.

16. Iqbal M, Rossoff L, McKeon K, Graver M, Scharf SM. Development of a giant bulla after lung volume reduction surgery. Chest 1999;116:1809-11.

17. Whitehead T, Slutsky AS. The pulmonary physician in critical care: ventilator induced lung injury. Thorax 2001;57: 635-42.

18. Fessler HE, Scharf M, Permutt S. Improvement in spirometry after lung volume reduction surgery. Am J Respir Crit Care Med 2002;165:34-40.

19. Ingenito EP, Loring SH, Moy ML, Mentzer SJ, Swanson SJ, Reilly JJ. Physiological characterization of variability in response to lung volume reduction surgery. J Appl Physiol 2003;94:20-30.

20. Mineo TC, Pompeo E, Rogliani P, et al. Effect of lung volume reduction surgery for severe emphysema on right ventricular function. Am J Respir Crit Care Med 2002;165:489-94.

21. Shitrit D, Fink G, Sahar G, Eidelman L, Saute M, Kramer MR. Successful lung transplantation following lung volume reduction surgery. Thorac Cardiovasc Surg 2003;51:274-6.

22. Senbaklavici O, Wisser W, Ozpeker C, et al. Successful lung volume reduction surgery brings patients into better condition for later lung transplantation. Eur J Cardiothorac Surg 2002;22:363-7.

23. Tutic M, Lardinois D, Imfeld S, et al. Lung-volume reduction surgery as an alternative or bridging procedure to lung transplantation. Ann Thorac Surg 2006;82:208-13.

24. Shen Y, Chen JY, Wey IC, et al. Single lung transplantation with concomitant controlateral lung volume reduction for end-stage emphysema. Nan Fang Yi Ke Da Xue Xue Bao 2007;27:895-6. 
Lung Volume Reduction Reoperations

Federico Tacconi, Eugenio Pompeo, Daniele Forcella, Mario Marino, Dimitrios

Varvaras and Tommaso C. Mineo

Ann Thorac Surg 2008;85:1171-1177

DOI: 10.1016/j.athoracsur.2007.12.009

Updated Information \& Services

References

Subspecialty Collections

Permissions \& Licensing

Reprints including high-resolution figures, can be found at:

http://ats.ctsnetjournals.org/cgi/content/full/85/4/1171

This article cites 24 articles, 15 of which you can access for free at: http://ats.ctsnetjournals.org/cgi/content/full/85/4/1171\#BIBL

This article, along with others on similar topics, appears in the following collection(s):

Lung - other

http://ats.ctsnetjournals.org/cgi/collection/lung_other

Requests about reproducing this article in parts (figures, tables) or in its entirety should be submitted to:

http://www.us.elsevierhealth.com/Licensing/permissions.jsp or email: healthpermissions@elsevier.com.

For information about ordering reprints, please email: reprints@elsevier.com 